$\angle$ Research Square
Preprints are preliminary reports that have not undergone peer review.

They should not be considered conclusive, used to inform clinical practice, or referenced by the media as validated information.

\title{
Ganoderma Lucidum Modulates Neuronal Structure and Function Regulatory Protein Expression and Protein-protein Interaction in Alzheimer's Disease Model Animals
}

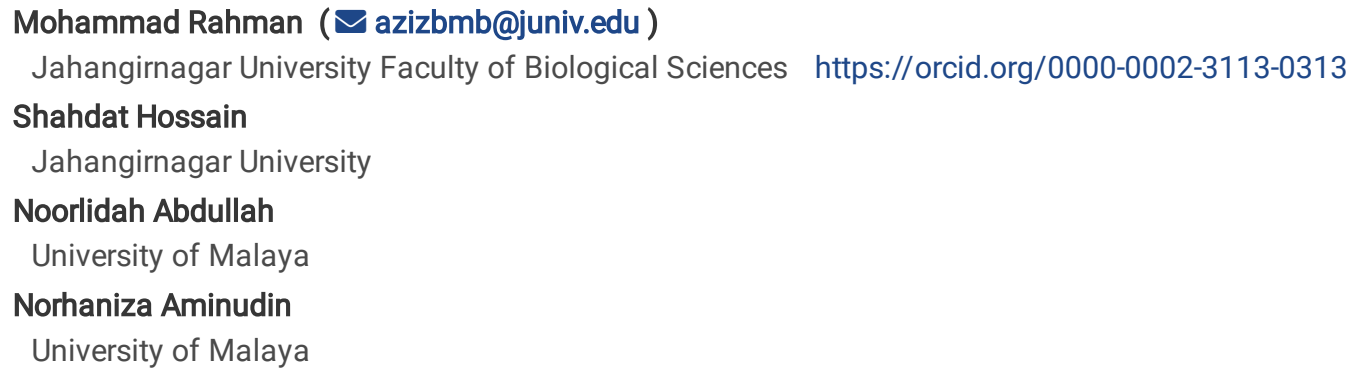

\section{Research}

Keywords: Alzheimer's disease, Neuroproteomics, lingenuity pathway analysis, Protein-protein interaction, STRING

Posted Date: November 12th, 2020

DOI: https://doi.org/10.21203/rs.3.rs-104135/v1

License: (c) (1) This work is licensed under a Creative Commons Attribution 4.0 International License. Read Full License 


\section{Abstract}

Background

Alzheimer's disease (AD) is the leading neurodegenerative disorder affecting memory, learning and behavior. Altered expression of proteins involved in neuronal structure and function is a recent observation of $A D$ pathogenesis. Modulation of altered protein expression seems promising in $A D$ therapeutics. In the present experiment, $A D$ ameliorating effect of medicinal mushroom Ganoderma lucidum had been evaluated through its effect on neuronal structure and function related protein expression pattern in AD model rats.

Methods

Wistar male rats (120 $\pm 5 \mathrm{gm}$ ) were divided into three groups: control (C), $A D(A)$ and G. lucidum hot water extract (HWE) fed AD (AE), each group containing 15 rats. AD model rats were prepared by infusing $A \beta_{1-42}$ (ab120959, abcam, USA) into the cerebral ventricles. Protein extraction from the brain samples was performed following homogenization of the hippocampus ( $50 \mathrm{mg}$ ) with lysis buffer ( $1 \mathrm{ml})$ using a homogenizer (Polytron PT 1200, Kinematica). Protein separation through SDS-PAGE and protein quantification through LC-chip MS/MS Q-TOF had been performed for label-free relative quantification. For statistical analyses, the data were exported to the Mass Profiler Professional (MPP) software and ANOVA $(P<0.05)$ had been performed to overcome the complications of false discovery associated with multiple test analyses. Functional interaction networks of the proteins were identified using the STRING (Search Tool for the Retrieval of Interacting Genes/Proteins) database (version 10.0; http://string-db.org/). For further identifying over-representing pathways and biological functions, the ingenuity pathway analysis (IPA), build version: 389077M, content version: 27821452, (Release date: 2016-06-14) was used (https://www.ingenuity.com/wp-content/themes/ingenuity-qiagen). Datasets of the proteins significantly expressed $(\mathrm{P}<0.05)$ and having log fold change of 1.5 and higher were uploaded ( $A D$ versus $C, A D$ versus $A E$ and $C$ versus $A E$ ).

Results

Among 2,212 proteins identified in the present study, 819 had been found to be differentially expressed. Of the differentially expressed ones, 40 proteins linked with neuronal structure and function regulation had been observed in the present study. AD rats manifested altered expression of proteins associated with neuronal structure and function. G. lucidum hot water treatment ameliorated the altered expression of those proteins.

Conclusions

Altered expression of hippocampal proteins is a hallmark of AD. Neuroproteomics regulatory approach towards AD amelioration seems promising. Inclusion of $G$. lucidum for proteomics based $A D$ therapeutics in regulation of the proteins involved in neuronal structure and function seem apt. Thus, $G$. lucidum could be considered as an $A D$ therapeutic agent.

\section{Introduction}

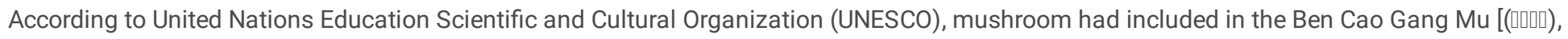
the first pharmacopoeaia in China, compiled during Ming dynasty (1590 AD)] as an aesthetic, spiritual and therapeutic agent [1-2]. Medicinal mushroom, Ling zhi (Ganoderma lucidum) has 2000 years-old reputation of usage in the Chinese medicine [3]. The State Pharmacopoeia of the People's Republic of China (2000) has incorporated G. Iucidum as the potent replenisher of Qi (life force), salient mind soothening and cough relieving as well as anti-asthmatic agent [2]. Modern medicinal sector also acknowledge its inclusion as a therapeutic agent against numerous physiological disorders including, but not limited to, antioxidant, anti-inflammatory, antitumor, anticancer, antimicrobial, immunomodulatory and hepatoprotective agent [3-7]. Content of more than 400 gano-components had accredited Ganoderma as the "fungal biofactory", "panacea" and the "elixir of life" [3-7]. Gano-components conferring medicinal values range from polysaccharides to triterpenes, sterols, proteins, peptides, fatty acids and vitamins [3-7]. Recently, utilization of $G$. lucidum in ameliorating neurodegenerative diseases like Alzheimer's disease (AD), have received epoch-making attention [8]. We have also observed promising effect of $G$. lucidum as an $A D$ therapeutic agent [9-15].

$A D$ is a neurodegenerative disorder affecting mostly the elderly people is posing threat to the ever increasing aged humanity of the world. Currently, more than 46 million people over the world have been suffering from AD and this number had been projected to double by 2050 [1617]. AD patients suffer from progressive loss of memory and learning abilities, behavioral abnormalities, disorientation about time and space, inability to smell and taste, difficulty in performing errands [17]. At severe stage, they become solely dependent on their family members and care-givers that lays extra economic burden on national and global health-care budget. Though the number of AD patients is skyrocketing, the world still awaits successful medication against this age-onset malady. AD occurs due to loss of neurons and synapses associated with

Page $2 / 15$ 
memory, learning and behavioral performances [17]. Since its identification in 1901, different hypotheses relating AD pathogenesis had been put forward. Among them, genetic predisposition, formation of amyloid beta (AB) plaques, neurofbirbillary tangles (NFT) and mutation had received attention [14]. Recently, proteomics approaches towards understanding the mechanism and modulation of AD pathogenesis has received high attention $[10,18-21]$. Differential expression of proteins between $A D$ and normal subjects would aid in formulating therapeutic strategies against $A D$. Though different approaches of $A D$ therapeutics had been linked with $G$. lucidum, there is scarcity of reports describing $A D$ neuroproteomics modulating effect of $G$. lucidum. Thus, the present study had been designed to evaluate the AD neuroproteomics modulatory effect of $G$. lucidum, especially the expression pattern of proteins regulating neuronal structure and function.

\section{Materials And Methods}

\section{a. Animals}

Wistar male rats (120 $\pm 5 \mathrm{gm}$ ) were divided into three groups: control (C), $A D(A)$ and G. lucidum hot water extract (HWE) fed $A D(A E)$, each group containing 15 rats. $A D$ model rats were prepared by infusing $A \beta_{1-42}$ (ab120959, abcam, USA) into the cerebral ventricles following an established method [22]. All the experimental protocols had been approved by the ethical permission committee, University of Malaya Institutional Animal Care and Use Committee (UMIACUC) [Ethics reference no. ISB/25/04/2013/NA (R)].

\section{b. Brain sample preparation and protein quantification}

Following our previously established method [10], rat brain samples had been prepared and protein quantified in the hippocampi of C, AD and $\mathrm{AE}$ rats. Briefly, protein extraction from the hippocampi had been performed by homogenization (brain sample $50 \mathrm{mg}$; lysis buffer $1 \mathrm{ml}$; homogenizer Polytron PT 1200, Kinematica); protein separation had been performed through SDS-PAGE [mini-PROTEAN tetra cell (165-8000, BIO-RAD, USA)] and protein quantification through LC-chip MS/MS Q-TOF [10]. To identify the proteins, the acquired MS/MS data were compared against the UniProtKB/Swiss Prot rat (Rattus norvegicus) database using the Spectrum Mill and X! Tandem. The differentially expressed proteins in the different groups were identified using their canonical sequence and proteins having fold change of at least 1.5 times were considered as the deregulated proteins. For validation of the identified proteins, the data were exported to the Scaffold database (version 4.5.1, Portland, USA). Proteins were grouped together if they would share at least two peptides and maintained their threshold level at $95.0 \%$ and $<1 \%$ false discovery rate (FDR) by the Peptide Prophet algorithm with Scaffold delta - mass correction for the matched peptide-spectra.

\section{c. Statistical analysis}

Data had been exported to the Mass Profiler Professional (MPP) software that analyzed depending on the MPP entities, the intensity of the total spectra of the proteins. Analysis of variance (ANOVA) had been performed to overcome the complications of false discovery associated with multiple test analyses.

\section{d. Bioinformatics and analysis of protein-protein interaction (PPI)}

Most of the proteins do not work singly rather they participate in complex network or scaffold and interact with others. Thus, analysis of the relevant protein-protein networks provides important information in deciphering any bio-molecular system. Functional interaction networks of the proteins were identified using the STRING (Search Tool for the Retrieval of Interacting Genes/Proteins) database (version 10.0; http://string$\mathrm{db}$.org/). STRING displays protein-protein interactions in a large network of connectivity and protein hubs. Active prediction methods that we used were experiments, neighborhood, databases, gene fusions, coexpression, cooccurrence and text mining, using high confidence (0.7). For further identifying over-representing pathways and biological functions, the ingenuity pathway analysis (IPA), build version: 389077M, content version: 27821452, (Release date: 2016-06-14) was used (https://www.ingenuity.com/wp-content/themes/ingenuity-qiagen). Datasets of the proteins significantly expressed $(P<0.05)$ and having log fold change of 1.5 and higher were uploaded $(A D$ versus $C, A D$ versus $A E$ and $C$ versus $A E)$.

\section{Results}

Liquid chromatography coupled tandem mass spectrometry (LC-MS/MS) had identified 2,212 proteins had been identified with protein threshold at $95.0 \%$, minimum peptide of 2 and peptide threshold at $0.1 \%$ FDR. Among them, 819 proteins were differentially expressed with statistical significance $(P<0.05)$. Among the significantly regulated $(P<0.05) 819$ proteins, 498 met the criteria of fold change (LogFC of 1.5) cut off value. Number of proteins linked with AD was 40 (Table 1). Number of commonly expressed proteins was 761 . The highest amount of proteins differentially expressed in the AD rats were those involved in maintaining neuronal structure and function (Table 1). 
Table 1

Significantly modified proteins with log fold change (FC) 1.5 and above

\begin{tabular}{|c|c|c|c|c|c|c|c|c|c|c|}
\hline \multirow[t]{2}{*}{ No. } & \multirow[t]{2}{*}{ Protein } & \multirow{2}{*}{$\begin{array}{l}\text { Swiss- } \\
\text { Prot } \\
\text { ID }\end{array}$} & \multirow{2}{*}{$\begin{array}{l}\text { M. wt. } \\
\text { (KDa) }\end{array}$} & \multirow{2}{*}{$\begin{array}{l}\mathrm{p} \\
\text { value }\end{array}$} & \multicolumn{2}{|l|}{$A D$ vs. $C$} & \multicolumn{2}{|l|}{$A D$ vs. $A E$} & \multicolumn{2}{|l|}{ AE vs. $C$} \\
\hline & & & & & Regulation & $\begin{array}{l}\text { Log } \\
\text { FC }\end{array}$ & Regulation & $\begin{array}{l}\text { Log } \\
\text { FC }\end{array}$ & Regulation & $\begin{array}{l}\log \\
F C\end{array}$ \\
\hline 1 & Syntaxin $1 \mathrm{~A}$ & Q9QXG3 & 33.38 & $1.09 \mathrm{E}-08$ & down & down & up & 15.97 & up & 16.31 \\
\hline 2 & Syntaxin-1B & P61265 & 33.47 & $3.15 \mathrm{E}-13$ & down & down & up & 16.21 & up & 16.56 \\
\hline 3 & Synaptogyrin-1 & Q62876 & 25.90 & 0.038714 & down & -10.26 & down & -15.72 & down & -5.45 \\
\hline 4 & Neuromodulin & P07936 & 23.72 & 0.042242 & down & -4.57 & up & 9.61 & up & 14.18 \\
\hline 5 & $\begin{array}{l}\text { Neural cell adhesion } \\
\text { molecule } 1\end{array}$ & P13596 & 95.46 & 0.036474 & down & -5.39 & up & 9.84 & up & 15.23 \\
\hline 6 & Synapsin-1 & P09951 & 74.16 & 5.39E-07 & up & 2.80 & & & down & -1.91 \\
\hline 7 & Synapsin-2 & Q63537 & 63.74 & $7.18 \mathrm{E}-05$ & up & 2.33 & & & & \\
\hline 8 & Annexin & Q66HH8 & 35.83 & 0.02747 & down & -9.43 & down & -15.78 & down & -6.36 \\
\hline 9 & Synaptophysin & P07825 & 33.60 & $1.22 \mathrm{E}-12$ & up & 16.92 & up & 16.92 & & \\
\hline 10 & Synaptotagmin-1 & P21707 & 47.74 & $1.15 \mathrm{E}-04$ & & & up & 1.58 & & \\
\hline 11 & Neuromodulin & P07936 & 23.72 & 0.042242 & down & -4.57 & up & 9.61 & up & 14.18 \\
\hline 12 & Neurochondrin & 035095 & 80.41 & 2.09E-09 & up & 17.00 & up & 2.20 & down & -14.80 \\
\hline 13 & Septin-2 & Q91Y81 & 41.76 & 7.80E-10 & & & down & -16.09 & down & -16.09 \\
\hline 14 & Isoform 2 of Septin-5 & $\begin{array}{l}\text { Q9JJM9- } \\
2\end{array}$ & 44.38 & $1.09 \mathrm{E}-11$ & & & down & -17.09 & down & -17.09 \\
\hline 15 & Neurofascin & R9PY05 & 138.87 & 0.024378 & down & -9.67 & up & 4.01 & up & 13.68 \\
\hline 16 & Serpina3n-like protein & E0A3N4 & 48.21 & 7.49E-04 & up & 2.41 & & & & \\
\hline 17 & Clathrin heavy chain & F1M779 & 193.32 & $8.61 \mathrm{E}-04$ & & & up & 1.63 & & \\
\hline 18 & Annexin & Q66HH8 & 35.83 & 0.02747 & down & -9.43 & down & -15.78 & down & -6.36 \\
\hline 19 & $\begin{array}{l}\text { Neurofilament heavy } \\
\text { polypeptide }\end{array}$ & P16884 & 115.66 & 0.006005 & down & -1.90 & & & up & 2.89 \\
\hline 20 & $\begin{array}{l}\text { Neurofilament light } \\
\text { polypeptide }\end{array}$ & P19527 & 61.39 & 0.004508 & down & -9.67 & up & 4.01 & up & 2.68 \\
\hline 21 & $\begin{array}{l}\text { Beta-soluble NSF } \\
\text { attachment protein }\end{array}$ & F8WFM2 & 33.90 & 3.83E-08 & & & up & 15.83 & up & 15.28 \\
\hline 22 & $\begin{array}{l}\text { Heat shock protein HSP } \\
\text { 90-alpha }\end{array}$ & P82995 & 85.21 & 2.71E-04 & up & 1.64 & & & & \\
\hline 23 & $\begin{array}{l}\text { Heat shock protein HSP } \\
\text { 90-beta }\end{array}$ & P34058 & 83.62 & $1.84 \mathrm{E}-04$ & up & 1.71 & & & & \\
\hline 24 & $\begin{array}{l}\text { Heat shock } 70 \text { kDa } \\
\text { protein 12A (Predicted), } \\
\text { isoform CRA_a }\end{array}$ & D3ZC55 & 75.17 & $9.72 \mathrm{E}-08$ & up & 16.07 & & & down & -14.60 \\
\hline 25 & $\begin{array}{l}\text { 14-3-3 protein } \\
\text { zeta/delta }\end{array}$ & P63102 & 27.94 & 2.73E-04 & up & 2.19 & & & down & -1.83 \\
\hline 26 & $14-3-3$ protein theta & P68255 & 28.06 & 0.0126 & up & 1.91 & & & & \\
\hline 27 & 14-3-3 protein eta & P68511 & 28.38 & 0.00353 & up & 2.03 & & & & \\
\hline 28 & 14-3-3 protein gamma & P61983 & 28.47 & 0.019343 & up & 1.69 & & & & \\
\hline
\end{tabular}

Here, C: control rats; AD: Alzheimer's disease model rats; AE: G. lucidum hot water extract fed AD rats; FC: fold change; KDa: killo Dalton; M. wt: molecular weight. 


\begin{tabular}{|c|c|c|c|c|c|c|c|c|c|c|}
\hline \multirow[t]{3}{*}{ No. } & \multirow[t]{3}{*}{ Protein } & \multirow{3}{*}{$\begin{array}{l}\text { Swiss- } \\
\text { Prot } \\
\text { ID }\end{array}$} & \multirow{3}{*}{$\begin{array}{l}\text { M. wt. } \\
\text { (KDa) }\end{array}$} & \multirow{3}{*}{$\begin{array}{l}\mathrm{p} \\
\text { value }\end{array}$} & \multicolumn{2}{|l|}{$A D$ vs. $C$} & \multicolumn{2}{|l|}{$A D$ vs. $A E$} & \multicolumn{2}{|l|}{ AE vs. C } \\
\hline & & & & & \multirow[t]{2}{*}{ Regulation } & \multirow{2}{*}{$\begin{array}{l}\text { Log } \\
\text { FC }\end{array}$} & \multirow[t]{2}{*}{ Regulation } & $\log$ & \multirow[t]{2}{*}{ Regulation } & \multirow{2}{*}{$\begin{array}{l}\text { Log } \\
\text { FC }\end{array}$} \\
\hline & & & & & & & & $\mathrm{FC}$ & & \\
\hline 29 & $\begin{array}{l}\text { 14-3-3 protein } \\
\text { beta/alpha }\end{array}$ & P35213 & 28.17 & 0.008179 & up & 1.86 & & & & \\
\hline 207 & $\begin{array}{l}\text { Ras-related protein Rap- } \\
1 \mathrm{~A}\end{array}$ & P62836 & 21.33 & 0.04164 & up & 5.30 & down & -10.44 & down & -15.75 \\
\hline 30 & $\begin{array}{l}\text { Ras-related protein Ral- } \\
\text { A }\end{array}$ & P63322 & 23.72 & $1.62 \mathrm{E}-12$ & & & down & -15.55 & down & -15.55 \\
\hline 31 & $\begin{array}{l}\text { Ras-related protein Rab- } \\
2 \mathrm{~A}\end{array}$ & P05712 & 23.71 & 2.27E-09 & up & 17.04 & & & down & -15.85 \\
\hline 32 & $\begin{array}{l}\text { Ras-related protein Rab- } \\
7 a\end{array}$ & P09527 & 23.79 & $1.85 \mathrm{E}-05$ & up & 17.05 & up & 3.55 & down & -13.50 \\
\hline 33 & $\begin{array}{l}\text { Ras-related protein Rab- } \\
\text { 11B }\end{array}$ & 035509 & 24.60 & $3.01 \mathrm{E}-11$ & up & 17.25 & up & 2.30 & down & -14.95 \\
\hline 34 & $\begin{array}{l}\text { Ras-related C3 } \\
\text { botulinum toxin } \\
\text { substrate } 1\end{array}$ & Q6RUV5 & 21.85 & $5.65 \mathrm{E}-10$ & & & down & -16.32 & down & -16.32 \\
\hline 35 & $\begin{array}{l}\text { Ras-related protein Rab- } \\
5 \mathrm{~A}\end{array}$ & MORC99 & 23.85 & 0.047559 & up & 10.75 & down & -4.90 & down & -15.64 \\
\hline 36 & $\begin{array}{l}\text { Ras-related protein Rab- } \\
18\end{array}$ & Q5EB77 & 23.26 & $6.58 \mathrm{E}-09$ & & & down & -14.47 & down & -14.47 \\
\hline 37 & $\begin{array}{l}\text { Isoform Syn2 of Alpha- } \\
\text { synuclein }\end{array}$ & $\begin{array}{l}\text { P37377- } \\
2\end{array}$ & 15.87 & $1.05 \mathrm{E}-11$ & & & down & -16.01 & down & -16.01 \\
\hline 38 & $\begin{array}{l}\text { Isoform } 2 \text { of Clathrin } \\
\text { coat assembly protein } \\
\text { AP180 }\end{array}$ & $\begin{array}{l}\text { Q05140- } \\
2\end{array}$ & 91.66 & 0.003282 & & & up & 3.08 & up & 1.99 \\
\hline 39 & $\begin{array}{l}\text { 4- } \\
\text { nitrophenylphosphatase } \\
\text { domain and non- } \\
\text { neuronal SNAP25-like } \\
\text { protein homolog } 1 \text { (C. } \\
\text { elegans), isoform } \\
\text { CRA_b }\end{array}$ & G3V728 & 33.63 & $1.22 \mathrm{E}-12$ & & & down & -15.22 & down & -15.22 \\
\hline 40 & $\begin{array}{l}\text { Excitatory amino acid } \\
\text { transporter } 1\end{array}$ & P24942 & 59.87 & 5.51E-10 & up & 17.81 & up & 3.44 & down & -14.37 \\
\hline
\end{tabular}

\section{Discussion}

\subsection{Differential expression of the significantly regulated proteins}

Differential expression of the proteins involved in neurotransmission, synaptic plasticity, neurogenesis, memory and learning related proteins such as neurochondrin, synaptophysin, synapsin-1, synapsin-2, synaptogyrin 3 (Syngr3), 4-aminobutyrate aminotransferase and 14-3-3 protein gamma were observed in the different rat groups (C, A and AE) (Table 1). Associative learning and long-term memory related proteins glutathione-S-transferase 3 and tenascin R were up regulated. Synaptic plasticity promoting Ras related protein Rab $5 \mathrm{a}$ and nerve growth factor (NGF) signaling Rap-1A were also among the significantly up-regulated group. Similar was the case for the heat shock proteins (HSP) involved in the regulation of neuronal migration (HSP 90-alpha) and apoptosis (HSp 60). Up-regulation was also observed for the proteins involved in post-synaptic excitatory potential (serine/threonine-protein phosphatase, syntaxin 1B), pre- and post-synaptic density (isoform 2 of clathrin coat assembly protein AP180) and tyrosine phosphorylation (hemopexin) in the AD compared to the mushroom-treated (AE) group.

Proteins involved in synaptic organization (neurofascin) and synaptic vesicle budding (ADP-ribosylation factor 1), vesicle mediated transport (syntaxin 1A), neuronal differentiation and development (Dihydropyrimidinase-related protein 1 and 2), axonogenesis (2', 3'-cyclic-nucleotide 3'phosphodiesterase), axonal choice point recognition (neuromodulin) and axonal transport (neurofilament light polypeptide) were also 
differentially expressed in the hippocampus of the three rat groups. Beta-soluble NSF attachment protein (SNAP- $\beta$ ) involved in the regulation of glutamatergic synaptic transmission, disassemble of SNARE complex and synaptic vesicle priming was also up regulated. In addition to these, differentially up regulated expression of glial fibrillary acidic protein (GFAP) was also observed. GFAP is involved in long-term synaptic potentiation, neurotransmitter uptake, neurogenesis, glial and Schwan cell proliferation.

In the present study, down-regulated expression of memory and learning related proteins in the AD group was observed when compared with both $C$ and $A E$ group. However, there was inter-group variation in the extent of fold change in case of the down-regulated proteins. In the $A D$ versus control group, down regulated expression of the proteins involved in dopamine decarboxylation, clusterin (stimulator of $A \beta$ and NFT), neuromodulin, neurofascin and NCAM 1 was observed. In the AD versus AE groups, a-synuclein, synaptogyrin 1 and transgelin-3 were among the most important down regulated proteins. In addition to these, neuromodulin, excitatory amino acid transporter and park 7 were the mostly up regulated proteins in the $\mathrm{AE}$ versus $\mathrm{C}$ groups (Table 1).

Following are the AD related proteins differentially expressed in the present study

\section{Syntaxin-1A}

Syntaxin-1 A regulates vesicular trafficking during exocytosis and trans-membranal protein insertion [22]. Decreased expression of syntaxin-1 A in the $A D$ rats might have affected synaptic functions [23]. Mushroom treatment might have synaptic function improving effect as upregulated expression of this protein has been observed in the mushroom-treated group.

\section{Synaptogyrin-1}

Synaptogyrin-1 is involved in maintaining short- and long-term synaptic plasticity. Level of hippocampal syntaxin-1 A and synaptogyrin-1 had been found to be reduced in line with $A D$ progression [24]. Its lowered expression in the AD and increased level in the AE rats reveals the ameliorating effect of G. Iucidum.

\section{Neuromodulin (GAP-3)}

Neuromodulin is a neuronal growth and neurite forming protein whose level decreases in AD brains. As an CSF biomarker, its lowered level has been found in other studies also [25-27]. However, in the present study, mushroom treatment (AE) has been found to increase the abundancy of this protein as is evidenced by the up-regulated expression.

\section{Neural cell adhesion molecule (NCAM)}

NCAM plays important role in brain development and increased level of NCAM 1 in transgenic AD mouse model (Tg2576) and of NCAM 2 in human $A D$ patients have been reported [28-29]. Current findings were compatible with the previous ones as G. Iucidum treatment helped increase the abundancy of NCAM.

\section{Endophilin A1}

Endophilin A1 is a membrane bending protein involved in CNS development, apoptosis, signal transduction and microtubule based movement. $A D$ rats' hippocampi showed decreased expression while the control and $A E$ rats experienced increased expression of endophilin $A 1$ in the present study. In the temporal neocortex of the AD patients, decreased level of endophilin A1 has been observed [30].

\section{Clathrin}

Clathrin group of proteins are involved in neuronal secretory functions and synaptic maintenance [31]. AD pathogenesis involves altered clathrin-associated membrane trafficking resulting in neurodegeneration [31]. Between the light and the heavy chains of clathrin, impaired distribution of the former has been linked with the AD pathogenesis [31-32]. Similar pattern was observed for the AD rats in the current experiment and an increasing trend following G. lucidum treatment (AE).

\section{Septin}

Septins are GTP-binding proteins found to be co-localized with the NFT in the AD brains [33]. Differential expressions of septins have been observed in the present study. Contrary to the findings of Musunury et al. (2014) [30] and Shin et al. (2004) [34], down-regulated expression of septin-2 had been observed in the AD versus AE group of the present study. As septin-2 is involved in synaptic plasticity, its down-regulation in the $A D$ versus $A E$ group bears supports to the synaptic dysfunction associated with the AD pathogenesis. However, its down-regulated expression in the CE versus $A E$ group is of intriguing. Interestingly, the isoform- 2 of septin- 5 had also been found down-regulated in both the $A D$ versus $A E$ and $A E$ versus $C$ groups which is compatible with the findings of Musunury et al. (2014) [30], who found similar expression status in the temporal brain neo-cortex of the $\mathrm{AD}$ patients. Thus, differential expression even of the different isoforms of the same protein might be 
implicated in the AD pathogenesis and corresponding modulation demands differential therapeutic strategy. Current observation of the $G$. lucidum HWE upon differential expression of different isoforms of septin is a unique finding that demands further studies.

\section{UCH L1}

Ubiquitin carboxyl-terminal hydrolase L1 (UCH L1) is an important enzyme for maintenance of cognitive and synaptic functions [35]. Conflicting information regarding its expression has been documented in different AD cases. Though most of the researchers have noticed decreased and oxidatively modified form of UCH L1 in AD subjects [36-38], Sultana et al (2007), reported its 1.31-fold increase in the AD brain hippocampi [39]. Increased expression of UCH L1 was observed in the G. lucidum-treated (AE) group.

\section{Soluble NSF-attachment protein beta (SNAP- $\beta$ )}

N-ethylmaleimide sensitive fusion proteins (NSF) are the part of APP and overexpressed in AD [40]. Soluble NSF-attachment proteins are involved in intracellular membrane fusion and vesicular trafficking. Among $\alpha-, \beta$ - and $\gamma$ - SNAPs, $\alpha$ - and $\gamma$ - SNAPs are expressed in different tissues while the $\beta$-SNAP is brain specific. In AD brain, differential expression and oxidized form of SNAP- $\beta$ had been detected through redox proteomics [41].

\section{Neuropolypeptide h3}

Neuropolypeptide h3 is a cholinergic neuro-stimulating peptide that falls in the phosphatidyloethanolamine binding protein group and is also known as Raf-kinase inhibitor protein (RKIP) and/or hippocampal cholinergic neurostimulating peptide (HCNP) [36]. Our finding of downregulated neuropolypeptide h3 is in agreement with those of Butterfield (2004) [42]. Oxidatively modified loss of function of neuropolypeptide h3 impairs phospholipid asymmetry that might be involved in extrusion of phosphatidyl serine to the outer membrane of neuron and signal for apoptosis and cause neuronal death [43]. Also, neuropolypeptide h3 mediated stimulation of acetylcholine esterase (AchE) becomes compromised and this effect is heightened when HNE interacts with AChE in presence of $A \beta$ (1-42) in synaptosome [44-45]. Thus, in AD brains, neuropolypeptide $\mathrm{h} 3$ is linked with cholinergic abnormalities and altered lipid metabolism that are the early events in AD pathogenesis [46].

\section{Annexin}

$A D$ rats showed increased expression of annexin in the hippocampi. Previous studies have linked increased plasma annexin5 with increased AD risk [47]. Transgenic AD mice (Tg2576) also expresses increased annexin in the brain cortex [48].

\section{Glycogen synthase kinase $3 \beta$ (GSK3 $\beta$ )}

Glycogen synthase kinase $3 \beta$ (GSK3 $\beta$ ) is a serine/threonine kinase having diversified regulatory functions ranging from glycogen metabolism to gene transcription. Overactivity of GSK-3 $\beta$ has been linked with elevated A $\beta$ production, tau hyperphosphorylation and impaired memory and learning activities [49]. Memory affecting mechanism of GSK-3 $\beta$ involves interruption of intra-neuronal anterograde mitochondrial transportation and causation of "mitochondrial traffic jam" [50-51].

\section{Serine/Threonine protein phosphatase}

Serine/Threonine protein phosphatase negatively regulate memory and learning abilities by impairing synaptic plasticity and LTP [52]. Upregulation of serine/threonine protein phosphatase in the $A D$ rats might contribute towards impaired memory and learning performance in the present study.

\section{Serine protease inhibitors (serpins)}

Serine protease inhibitors (serpins) regulate proteolytic processing of proteins. Previous studies indicated their increased level in plasma and CSF of AD patients [53]. We also observed increased expression of serpins (a1-antitrypsin) in the AD rats' hippocampi. Alpha 1-antitrypsin (A1AT) has been reported to be co-localizing with A $\beta$ plaques and NFTs [54].

\subsection{PPI network of the upregulated protein clusters in the AD vs AE group}

In the $A D$ versus $A E$ group, the most notable protein networks included those involved in the biological processes such as redox mechanisms, neurogenesis, neurotransmission, neuronal development and metabolism (Fig. 1). Interacted protein networks involved in molecular functions such as SNARE binding, syntaxin binding, syntaxin-1 binding were also enriched (Fig. 1).

The main network of the upregulated proteins can be divided into several subsets with respect to their gene content such as sub-set 1 consisting of synaptogamin-1, syntaxin 1A, syntaxin 1B, beta soluble NSF attachment protein (Syt1, Stx1a, Stx1b and Napb), sub-set 2 
involving AP2 forming proteins and clathrin heavy chain (Ap2a2, Ap2a1, C/tc), sub-set 3 consisting of metabolic enzymes NADH dehydrogenase, dihydrolipoyllysine-residue acetyltransferase component of pyruvate dehydrogenase complex, pyruvate dehydrogenase E1 component subunit beta and isocitrate dehydrogenase (Ndufv2, Ndufa9, Dlat, Pdhb and Idh3a) and those involved in signal transduction, membrane trafficking and cytoskeletal maintenance (Ubb, Vcp, C3, Rab7a, Rab11b, Gpi and HK1) (Fig. 1). Besides the main network, two other protein-protein interaction networks involved immune-regulatory proteins (Igg-2a, Igh-1a, IgkC and Crp) and proteins associated with Ca ${ }^{2+}{ }_{-}$ mediated signaling and metabolism (Calm1, Camk2a, Camk2b and Ppp3ca) (Fig. 1).

\subsection{Identification of functional pathway interaction through IPA}

Based on ingenuity pathway analysis Knowledge Base (IPAKB), genes are transformed into relevant networks. In the network, relationships among the genes are expressed as the "edges" and genes become connected with each other only if there is any path among them in the global network. In this case, molecules from the dataset that are uploaded are called the "focus molecules". Core analysis of IPA was performed to interpret the datasets in the form of their functional networks. In the IPAKB, corresponding objects were mapped with the protein identifiers [55]. Depending on the physical interaction (direct relationship) among the eligible proteins, IPAKB generated the networks and the score (probability value) of the networks [55]. Higher the network connectivity, greater is the representation of significant biological functions of the relevant genes [55]. Statistical justification of the network connectivity has been performed through measuring " $p$ scores (-log10 $p$ value, Fisher's exact test)" and "network score". Network score has also been measured through Fisher's exact test that is based on the focus protein and biological functions and thus shows the relevancy of the analysis.

\subsubsection{Functional network in AD vs AE}

IPA of the AD vs AE identified 20 networks of which the top-most one had score of 75 and focus molecules 83 among 140 total selected molecules (Fig. 2). The top-most network functions include cell death and survival, cell morphology and organ morphology. The second one had score of 56 and focus molecules 73 among 140 total selected molecules (Fig. 2). The second-top network related functions include molecular transport, cell signaling, nervous system development and function categories. The third network had score of 8 and 25 focus molecules among 135 total selected molecules involved in CVD and functions, cellular and organismal development (Fig. 2).

Up to present day, about 96 proteins have been reported to be linked with AD [30]. Most of the differentially expressed proteins identified in the present study fall within that category. The reason for not detecting direct expression of APP or A in the AD rats of the present study might be that $A \beta$ was infused intra-ventricularly and this does not fall under the category of expression or repression. But its effect is revealed through up- and/or - down regulation of multiple proteins in the AD subjects. Provided the same amount of protein being processed for quantification, variability in the output may be considered due to reduced accessibility of the AD proteins towards trypsin digestion as the proteins in $A D$ subjects are much aggregated and less soluble compared to the controls. Importantly, inability to detect proteins of target does not imply their absence in the sample; rather it is an indication of their differential expression. As the AD rats had been found to experience impaired memory and learning activities and altered expression and networks (both interacting and functional pathways, as revealed by the STRING and IPA analysis, respectively) of the memory and learning related proteins, differential expression of the proteins might be attributed to the infused $A \beta$ in the respective model animals [8-12]. On the other hand, proteins up- and down-regulated in the control and G. lucidum treated animals might have been involved in improving those derangements and thus ameliorating the AD consequences as observed through memory related tests described elsewhere [8-12]. Another important feature of the present study is that some of the proteins differentially expressed in the AD model rats are highly interacted with each other and formed pathway-based functional networks. This inter-relationship sets a novel ground for $A D$ therapeutics. Thus, findings of the current research suggest a novel target for AD pathogenesis management and incorporation of $G$. lucidum as an $A D$ ameliorating agent seems pertinent. Differential expression of the proteins in the mushroom-fed $A D$ rats might either be an adaptive response or protective strategy against $A \beta$-mediated stresses. Admittedly, the regulated proteins, identified in the current experiment but not previously been studied, warrants extensive exploration for much conclusive remarks. In this endeavor, western blot analysis of the mostly regulated proteins for validation of the current findings is the immediate future aspect of the present study.

\section{Conclusion}

Present study indicates the Alzheimer's disease modulatory effect of medicinal mushroom G. lucidum through differential expression of neuronal structure and function related proteins, restoration of disrupted protein-protein interaction network and maintenance of integrated pathways. Thus, utilization of G. Iucidum in AD therapeutics seems promising. However, further studies should be carried out to determine therapeutic dosage, toxicity and safety.

\section{Abbreviations}


Alzheimer's disease model rat; AE:Ganoderma lucidum hot water extract fed Alzheimer's disease model rat; C:Control rat; AD:Alzheimer's disease; GL:Ganoderma lucidum; HWE:Hot water extract; FC:fold change of protein:KDa:Killo Dalton; M.wt:Molecular weight; PPI:Protein-protein interaction; IPA:Ingenuity pathway analysis; STRING:Search Tool for the Retrieval of Interacting Genes/Proteins.

\section{Declarations}

Ethics approval and consent to participate: All the experimental protocols had been approved by the ethical permission committee, University of Malaya Institutional Animal Care and Use Committee (UMIACUC) [Ethics reference no. ISB/25/04/2013/NA (R)].

Consent for publication: All authors consented to publish.

Availability of data and material: Not applicable.

Competing interests: Authors declare no competing interest.

Funding: Authors gratefully acknowledge the financial support from Jahangirnagar University, Bangladesh; University Grants Commission (UGC) of Bangladesh; Bangladesh Ministry of Education; Ministry of National Science, Communication and Information Technology of Bangladesh and University of Malaya, Malaysia.

Authors' contributions: Mohammad Azizur Rahman designed and conducted the experiments, interpreted outcomes, composed manuscripts. Other authors supervised the experiments.

Acknowledgement: Authors gratefully acknowledge the personnels and institutions that provided laboratory and equipmental support in conducting this research.

\section{References}

1. http://www.unesco.org/new/en/communication-and-information/memory-of-the-world/register/full-list-of-registered-heritage/registeredheritage-page-1/ben-cao-gang-mu-compendium-of-materia-medica/

2. The State Pharmacopoeia Commission of P. R. China. State Pharmacopoeia Commission of the People's Republic of China.Beijing, China: Chemical Industry Press; 2000.

3. Wachtel-Galor S, Yuen J, Buswell JA, et al. Ganoderma lucidum (Lingzhi or Reishi): A Medicinal Mushroom. In: Benzie IFF, Wachtel-Galor S, editors. Herbal Medicine: Biomolecular and Clinical Aspects. 2nd edition. Boca Raton (FL): CRC Press/Taylor \& Francis; 2011. Chapter 9. https://www.ncbi.nlm.nih.gov/books/NBK92757/

4. Upton R. American Herbal Pharmacopeia and Therapeutic Compendium: Reishi Mushroom, Ganoderma lucidum. Standards of Analysis, Quality Control, and Therapeutics. U.S.A. Canada: Santa Cruz; 2000.

5. Rahman MA, Abdullah N, Aminudin N. Evaluation of the antioxidative and hypo-cholesterolemic effects of lingzhi or reishi medicinal mushroom, Ganoderma lucidum (Agaricomycetes), in ameliorating cardiovascular disease. Int J Med Mushrooms. 2018;20(10):961-969. doi:10.1615/IntJMedMushrooms.2018028370.

6. Paterson RRM. Ganoderma - A therapeutic fungal biofactory. Phytochem 2006, 67 (18):1985-2001.Rahman M A, Abdullah N, Aminudin N (2017). Corroborative assessment of mushroom as the graceful ageing and lifespan promoting agent. Biointerface Research in Applied Chemistry. 7:3:1-13 page id 2048.

7. Qin LH, Wang C, Qin LW, Liang YF, Wang GH. Spore powder of Ganoderma lucidum for Alzheimer's disease: A protocol for systematic review. Medicine (Baltimore). 2019 Feb;98(5):e14382. doi: 10.1097/MD.0000000000014382. PMID: 30702632; PMCID: PMC6380698.

8. Rahman MA, Hossain S, Abdullah N, Aminudin N (2020). Lingzhi or Reishi Medicinal Mushroom, Ganoderma lucidum (Agaricomycetes) Ameliorates Non-spatial Learning and Memory Deficits in Rats with Hypercholesterolemia and Alzheimer's Disease. International Journal of Medicinal Mushrooms. DOI: 10.1615/IntJMedMushrooms.2020036354.

9. Rahman M A, Hossain S, Abdullah N, Aminudin N (2019). Brain proteomics links oxidative stress with metabolic and cellular stress response proteins in behavioural alteration of Alzheimer's disease model rats. AlMS Neuroscience, 6(4): 299-315. doi: 10.3934/Neuroscience.2019.4.299. PMID: 32341985; PMCID: PMC7179348.

10. Rahman MA, Hossain S, Abdullah N, Aminudin N (2020). Ganoderma lucidum Ameliorates Spatial Memory and Memory-Related Protein Markers in Hypercholesterolemic and Alzheimer's Disease Model Rats. Archives of Neurology and Neurologica Disorders. 3(2):117 - 129.

11. Rahman MA, Hossain MS, Abdullah N, Aminudin N. Validation of Ganoderma lucidum against hypercholesterolemia and Alzheimer's disease. Eur J Biol Res. 2020 Aug 31;10(4):314-25. http://dx.doi.org/10.5281/zenodo.4009588. 
12. Rahman MA, Hossain S, Abdullah N, Aminudin N. lingzhi or reishi medicinal mushroom, Ganoderma lucidum (Agaricomycetes) ameliorates spatial learning and memory deficits in rats with hypercholesterolemia and alzheimer's disease. Int J Med Mushrooms. 2020;22(1):93-103. doi:10.1615/IntJMedMushrooms.2020033383.

13. Rahman MA, Abdullah N, Aminudin N. Interpretation of mushroom as a common therapeutic agent for Alzheimer's disease and cardiovascular diseases. Crit Rev Biotechnol. 2016;36(6):1131-1142. doi:10.3109/07388551.2015.1100585.

14. Rahman MA, Hossain S, Abdullah N, Aminudin N (2020). Restoration of Perturbed Ca ${ }^{2+}$ Regulatory Proteins in Alzheimer's disease Model Rats by Ganoderma lucidum. Alzheimer's disease and Dementia.

15. https://www.who.int/life-course/news/world-report-on-ageing/en/. Accessed: October, 2020.

16. Alzheimer's Association. 2020 Alzheimer's Disease Facts and Figures. Alzheimers Dement 2020;16(3):391. https://www.alz.org/media/Documents/alzheimers-facts-and-figures.pdf

17. Rahman M A, Abdullah N, Aminudin N (2020). Hippocampal Proteomics Profiling along with Protein-Protein Interaction Analysis Elucidates Alzheimer's Disease Pathways and Genes. Proteomics Bioinformatics. 2(2): 68-83.

18. Bai B, Wang X, Li Y, Chen PC, Yu K, Dey KK, Yarbro JM, Han X, Lutz BM, Rao S, Jiao Y, Sifford JM, Han J, Wang M, Tan H, Shaw TI, Cho JH, Zhou S, Wang H, Niu M, Mancieri A, Messler KA, Sun X, Wu Z, Pagala V, High AA, Bi W, Zhang H, Chi H, Haroutunian V, Zhang B, Beach TG, Yu G, Peng J. Deep Multilayer Brain Proteomics Identifies Molecular Networks in Alzheimer's Disease Progression. Neuron. 2020 Mar 18;105(6):975-991.e7. doi: 10.1016/j.neuron.2019.12.015. Epub 2020 Jan 8. Erratum in: Neuron. 2020 May 20;106(4):700. PMID: 31926610; PMCID: PMC7318843.

19. Johnson ECB, Dammer EB, Duong DM, Yin L, Thambisetty M, Troncoso JC, Lah JJ, Levey Al, Seyfried NT. Deep proteomic network analysis of Alzheimer's disease brain reveals alterations in RNA binding proteins and RNA splicing associated with disease. Mol Neurodegener. 2018 Oct 4;13(1):52. doi: 10.1186/s13024-018-0282-4. PMID: 30286791; PMCID: PMC6172707.

20. Butterfield DA, Boyd-Kimball D, Castegna A. Proteomics in Alzheimer's disease: insights into potential mechanisms of neurodegeneration. J Neurochem. 2003 Sep;86(6):1313-27. doi: 10.1046/j.1471-4159.2003.01948.x. PMID: 12950441.

21. F Fang, Y Ning, F Zhanhui, L Xiangqin, Y Yong. Alzheimer's disease animal model by aluminum, beta-amyloid and transforming growth factor beta-1, Aging. Neurodegen. 1 (2013) 15-19.

22. Sudhof TC. The synaptic vesicle cycle. Annu Rev Neurosci. 2004;27:509-47. doi: 10.1146/annurev.neuro.26.041002.131412. PMID: 15217342.

23. Shevchenko G, Wetterhall M, Bergquist J, Höglund K, Andersson LI, Kultima K. Longitudinal characterization of the brain proteomes for the tg2576 amyloid mouse model using shotgun based mass spectrometry. J Proteome Res. 2012 Dec 7;11(12):6159-74. doi: 10.1021/pr300808h. Epub 2012 Oct 30. PMID: 23050487.

24. Saetre P, Jazin E, Emilsson L. Age-related changes in gene expression are accelerated in Alzheimer's disease. Synapse. 2011 Sep;65(9):971-4. doi: 10.1002/syn.20933. Epub 2011 Apr 11. PMID: 21425351.

25. Babić M, Svob Štrac D, Mück-Šeler D, Pivac N, Stanić G, Hof PR, Simić G. Update on the core and developing cerebrospinal fluid biomarkers for Alzheimer disease. Croat Med J. 2014 Aug 28;55(4):347-65. doi: 10.3325/cmj.2014.55.347. PMID: 25165049; PMCID: PMC4157375.

26. Bogdanovic N, Davidsson P, Volkmann I, Winblad B, Blennow K. Growth-associated protein GAP-43 in the frontal cortex and in the hippocampus in Alzheimer's disease: an immunohistochemical and quantitative study. J Neural Transm (Vienna). 2000;107(4):463-78. doi: 10.1007/s007020070088. PMID: 11215757.

27. Blennow K, Zetterberg H. Biomarkers for Alzheimer's disease: current status and prospects for the future. J Intern Med. 2018 Dec;284(6):643-663. doi: 10.1111/joim.12816. Epub 2018 Aug 19. PMID: 30051512.

28. Shevchenko G, Sjödin MO, Malmström D, Wetterhall M, Bergquist J. Cloud-point extraction and delipidation of porcine brain proteins in combination with bottom-up mass spectrometry approaches for proteome analysis. J Proteome Res. 2010 Aug 6;9(8):3903-11. doi: 10.1021/pr100116k. PMID: 20586484.

29. Todaro L, Puricelli L, Gioseffi H, Guadalupe Pallotta M, Lastiri J, Bal de Kier Joffé E, Varela M, Sacerdote de Lustig E. Neural cell adhesion molecule in human serum. Increased levels in dementia of the Alzheimer type. Neurobiol Dis. 2004 Mar;15(2):387-93. doi: 10.1016/j.nbd.2003.11.014. PMID: 15006709.

30. Musunuri S, Wetterhall M, Ingelsson M, Lannfelt L, Artemenko K, Bergquist J, Kultima K, Shevchenko G. Quantification of the brain proteome in Alzheimer's disease using multiplexed mass spectrometry. J Proteome Res. 2014 Apr 4;13(4):2056-68. doi: 10.1021/pr401202d. Epub 2014 Mar 19. PMID: 24606058.

31. Cao Y, Xiao Y, Ravid R, Guan ZZ. Changed clathrin regulatory proteins in the brains of Alzheimer's disease patients and animal models. J Alzheimers Dis. 2010;22(1):329-42. doi: 10.3233/JAD-2010-100162. PMID: 20847448.

32. Nakamura Y, Takeda M, Yoshimi K, Hattori H, Hariguchi S, Hashimoto S, Nishimura T. Involvement of clathrin light chains in the pathology of Pick's disease; implication for impairment of axonal transport. Neurosci Lett. 1994 Oct 10;180(1):25-8. doi: 10.1016/0304-

Page $10 / 15$ 
3940(94)90905-9. PMID: 7533277.

33. Kinoshita A, Kinoshita M, Akiyama H, Tomimoto H, Akiguchi I, Kumar S, Noda M, Kimura J. Identification of septins in neurofibrillary tangles in Alzheimer's disease. The American journal of pathology. 1998 Nov 1;153(5):1551-60.

34. Shin SJ, Lee SE, Boo JH, Kim M, Yoon YD, Kim SI, Mook-Jung I. Profiling proteins related to amyloid deposited brain of Tg2576 mice. Proteomics. 2004 Nov;4(11):3359-68.

35. Gong B, Cao Z, Zheng P, Vitolo OV, Liu S, Staniszewski A, Moolman D, Zhang H, Shelanski M, Arancio O. Ubiquitin hydrolase Uch-L1 rescues $\beta$-amyloid-induced decreases in synaptic function and contextual memory. Cell. 2006 Aug 25;126(4):775-88.

36. Castegna A, Aksenov M, Thongboonkerd V, Klein JB, Pierce WM, Booze R, Markesbery WR, Butterfield DA. Proteomic identification of oxidatively modified proteins in Alzheimer's disease brain. Part II: dihydropyrimidinase-related protein 2, a-enolase and heat shock cognate 71. Journal of neurochemistry. 2002 Sep;82(6):1524-32.

37. Choi J, Levey Al, Weintraub ST, Rees HD, Gearing M, Chin LS, Li L. Oxidative modifications and down-regulation of ubiquitin carboxylterminal hydrolase L1 associated with idiopathic Parkinson's and Alzheimer's diseases. Journal of Biological Chemistry. 2004 Mar 26;279(13):13256-64.

38. Minjarez B, Rustarazo M, Valero L, Sanchez del Pino MM, González-Robles A, Sosa-Melgarejo JA, Luna-Muñoz J, Mena R, Luna-Arias JP. Identification of polypeptides in neurofibrillary tangles and total homogenates of brains with Alzheimer's disease by tandem mass spectrometry. Journal of Alzheimer's Disease. 2013 Jan 1;34(1):239-62.

39. Sultana R, Boyd-Kimball D, Cai J, Pierce WM, Klein JB, Merchant M, Butterfield DA. Proteomics analysis of the Alzheimer's disease hippocampal proteome. Journal of Alzheimer's Disease. 2007 Jan 1;11(2):153-64.

40. Cottrell BA, Galvan V, Banwait S, Gorostiza O, Lombardo CR, Williams T, Schilling B, Peel A, Gibson B, Koo EH, Link CD. A pilot proteomic study of amyloid precursor interactors in Alzheimer's disease. Annals of neurology. 2005 Aug;58(2):277-89.

41. Butterfield DA, Perluigi M, Sultana R. Oxidative stress in Alzheimer's disease brain: new insights from redox proteomics. European journal of pharmacology. 2006 Sep 1;545(1):39-50.

42. Butterfield DA. Proteomics: a new approach to investigate oxidative stress in Alzheimer's disease brain. Brain research. 2004 Mar $12 ; 1000(1-2): 1-7$.

43. Daleke DL, Lyles JV. Identification and purification of aminophospholipid flippases. Biochimica et Biophysica Acta (BBA)-Molecular and Cell Biology of Lipids. 2000 Jun 26;1486(1):108-27.

44. Butterfield DA, Castegna A, Lauderback CM, Drake J. Evidence that amyloid beta-peptide-induced lipid peroxidation and its sequelae in Alzheimer's disease brain contribute to neuronal death. Neurobiology of aging. 2002 Sep 1;23(5):655-64.

45. Morris JC. Challenging assumptions about Alzheimer's disease: mild cognitive impairment and the cholinergic hypothesis. Annals of neurology. 2002 Feb 1;51(2):143-4.

46. Butterfield DA, Perluigi M, Sultana R. Oxidative stress in Alzheimer's disease brain: new insights from redox proteomics. European journal of pharmacology. 2006 Sep 1;545(1):39-50.

47. Sohma H, Imai SI, Takei N, Honda H, Matsumoto K, Utsumi K, Matsuki K, Hashimoto E, Saito T, Kokai Y. Evaluation of annexin A5 as a biomarker for Alzheimer's disease and dementia with lewy bodies. Frontiers in aging neuroscience. 2013 Apr 5;5:15.

48. Yamaguchi M, Kokai Y, Imai SI, Utsumi K, Matsumoto K, Honda H, Mizue Y, Momma M, Maeda T, Toyomasu S, Ito YM. Investigation of annexin A5 as a biomarker for Alzheimer's disease using neuronal cell culture and mouse model. Journal of neuroscience research. 2010 Sep;88(12):2682-92.

49. Vanleuven F. GSK3 and Alzheimer's disease: facts and fiction. Frontiers in molecular neuroscience. 2011 Aug 26;4:17.

50. Correia SC, Perry G, Moreira PI. Mitochondrial traffic jams in Alzheimer's disease-pinpointing the roadblocks. Biochimica et Biophysica Acta (BBA)-Molecular Basis of Disease. 2016 Oct 1;1862(10):1909-17.

51. Zempel H, Thies E, Mandelkow E, Mandelkow EM. A $\beta$ oligomers cause localized Ca2+ elevation, missorting of endogenous Tau into dendrites, Tau phosphorylation, and destruction of microtubules and spines. Journal of Neuroscience. 2010 Sep 8;30(36):11938-50.

52. Jouvenceau A, Hédou G, Potier B, Kollen M, Dutar P, Mansuy IM. Partial inhibition of PP1 alters bidirectional synaptic plasticity in the hippocampus. European Journal of Neuroscience. 2006 Jul;24(2):564-72.

53. Nielsen HM, Minthon L, Londos E, Blennow K, Miranda E, Perez J, Crowther DC, Lomas DA, Janciauskiene SM. Plasma and CSF serpins in Alzheimer disease and dementia with Lewy bodies. Neurology. 2007 Oct 16;69(16):1569-79.

54. Gollin PA, Kalaria RN, Eikelenboom P, Rozemuller A, Perry G. a1-Antitrypsin and a1-antichymotrypsin are in the lesions of Alzheimer's disease. Neuroreport. 1992 Feb 1;3(2):201-3.

55. James R, Searcy JL, Le Bihan T, Martin SF, Gliddon CM, Povey J, Deighton RF, Kerr LE, McCulloch J, Horsburgh K. Proteomic analysis of mitochondria in APOE transgenic mice and in response to an ischemic challenge. Journal of Cerebral Blood Flow \& Metabolism. 2012, 


\section{Figures}

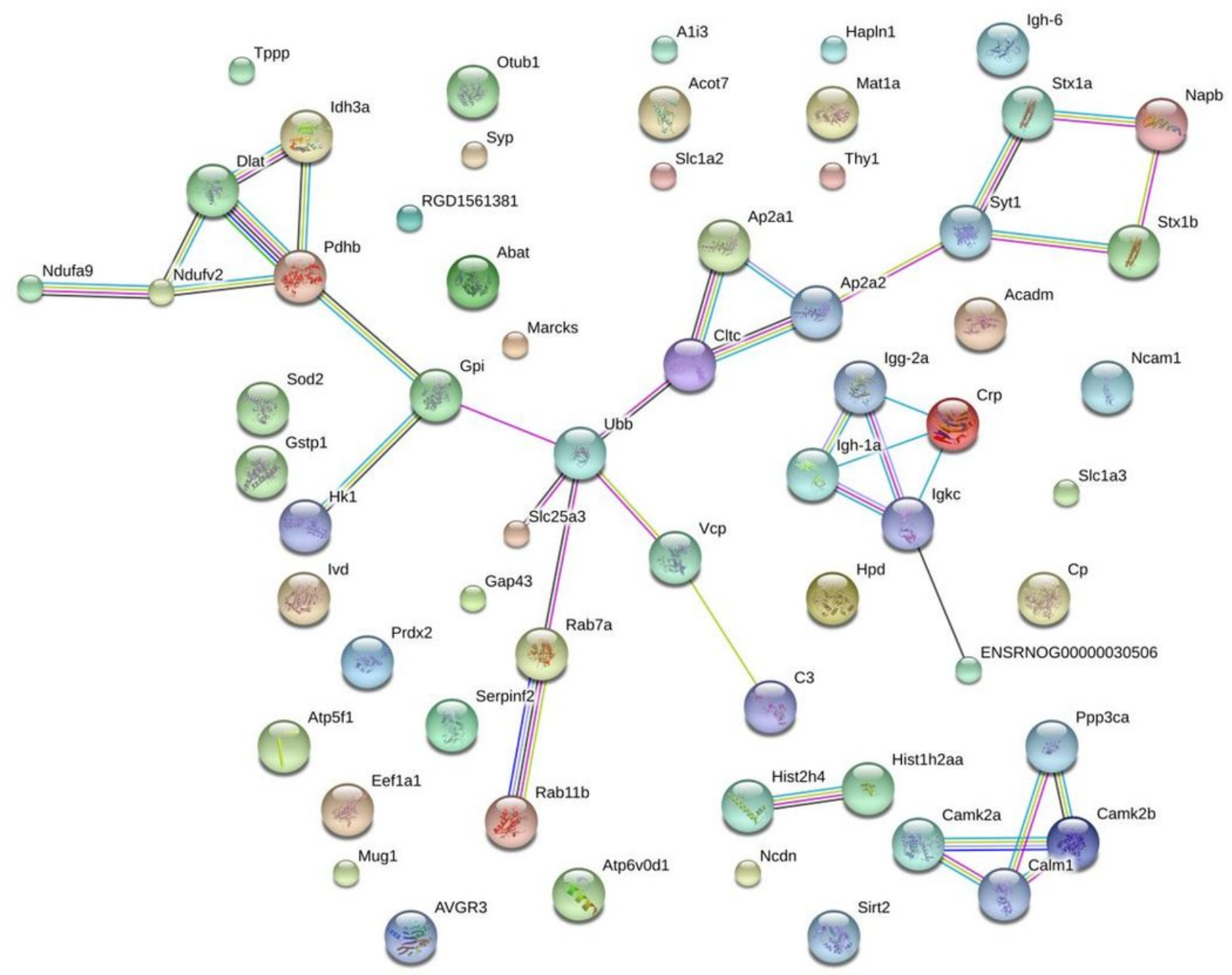

\section{Figure 1}

Protein-protein interaction (PPI) of $A D$ versus $A E$ rat groups. 


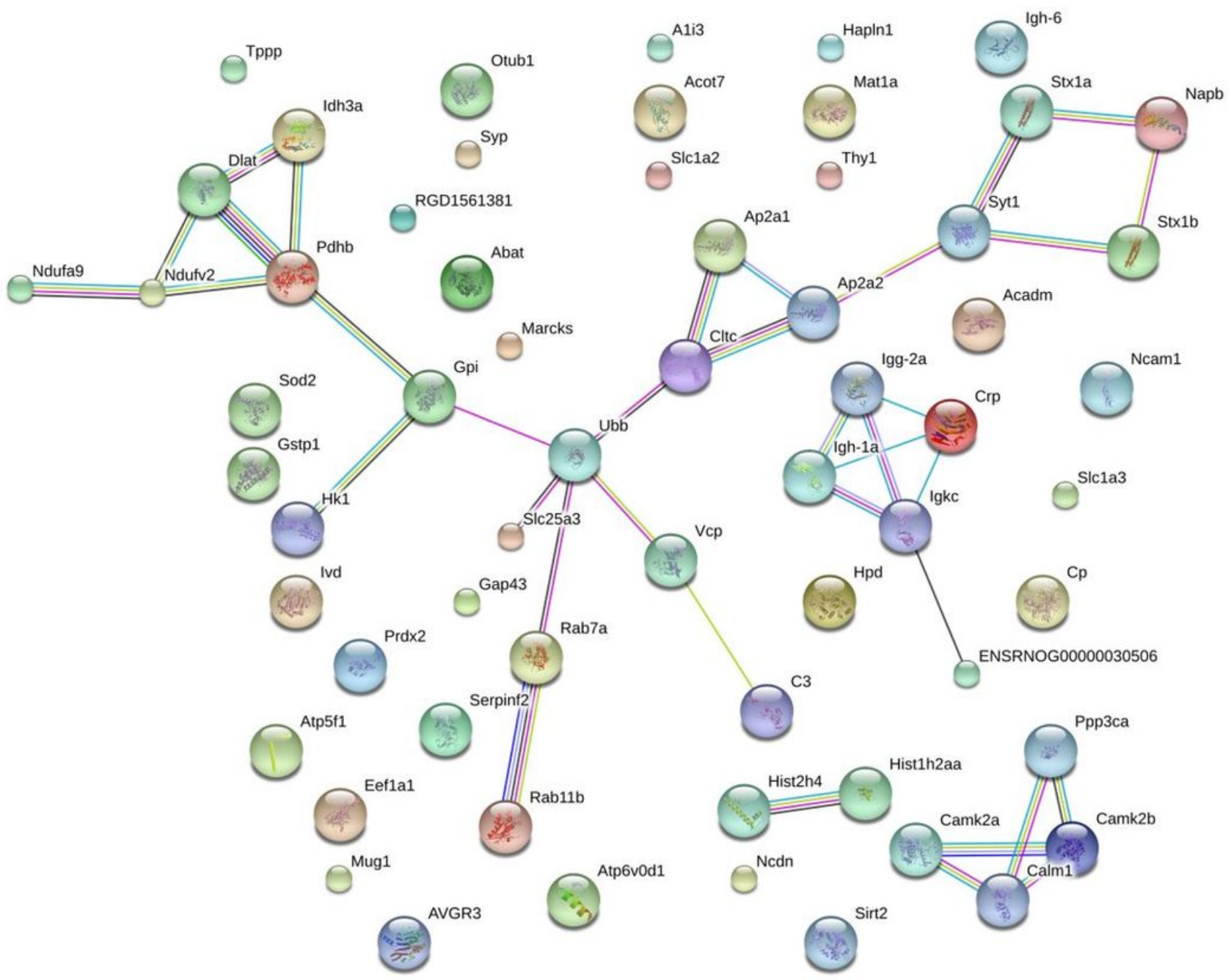

Figure 1

Protein-protein interaction (PPI) of AD versus AE rat groups. 


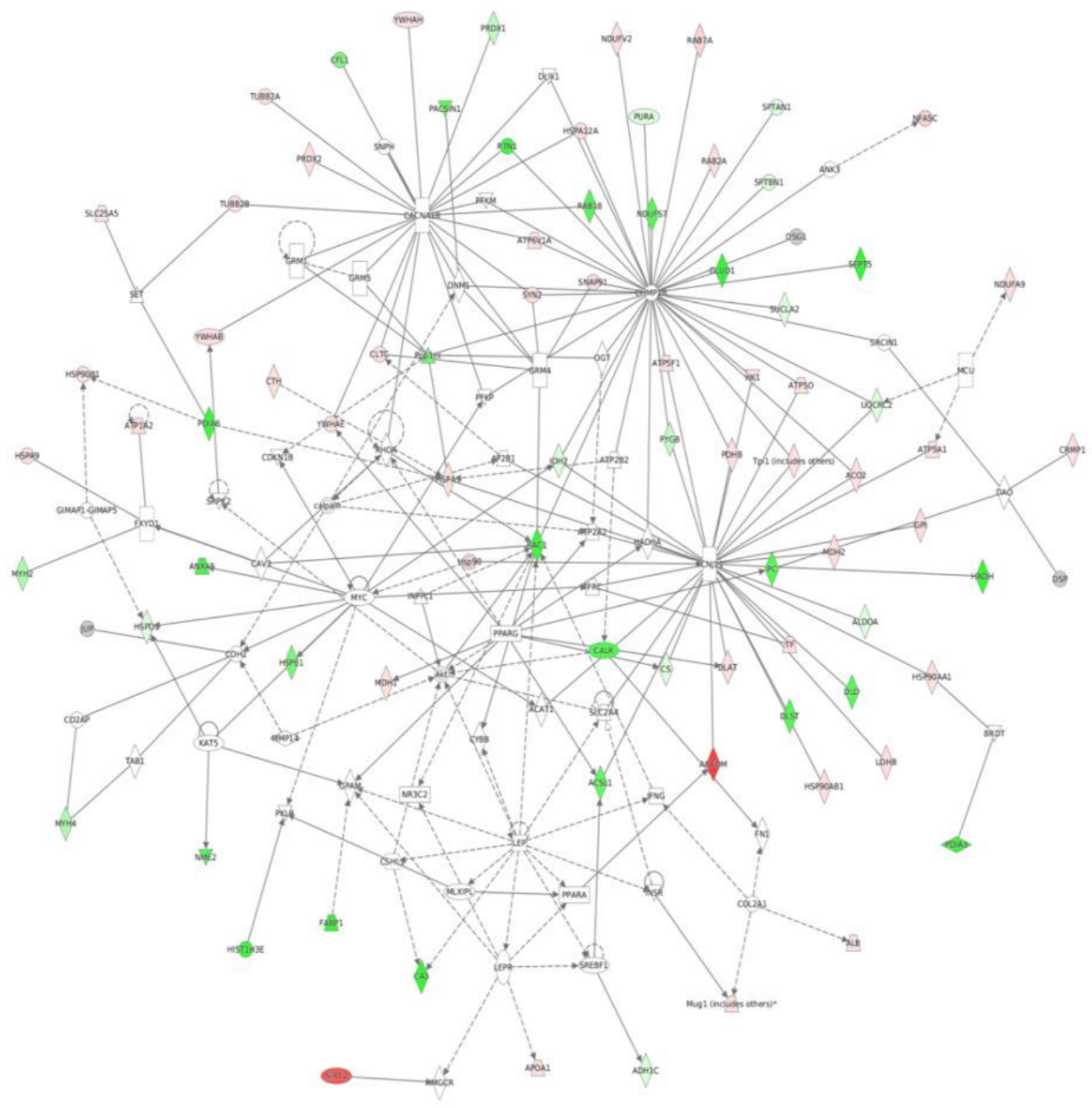

Figure 2

Integrated pathway analysis (IPA) of $A D$ versus $A E$ rat groups. 


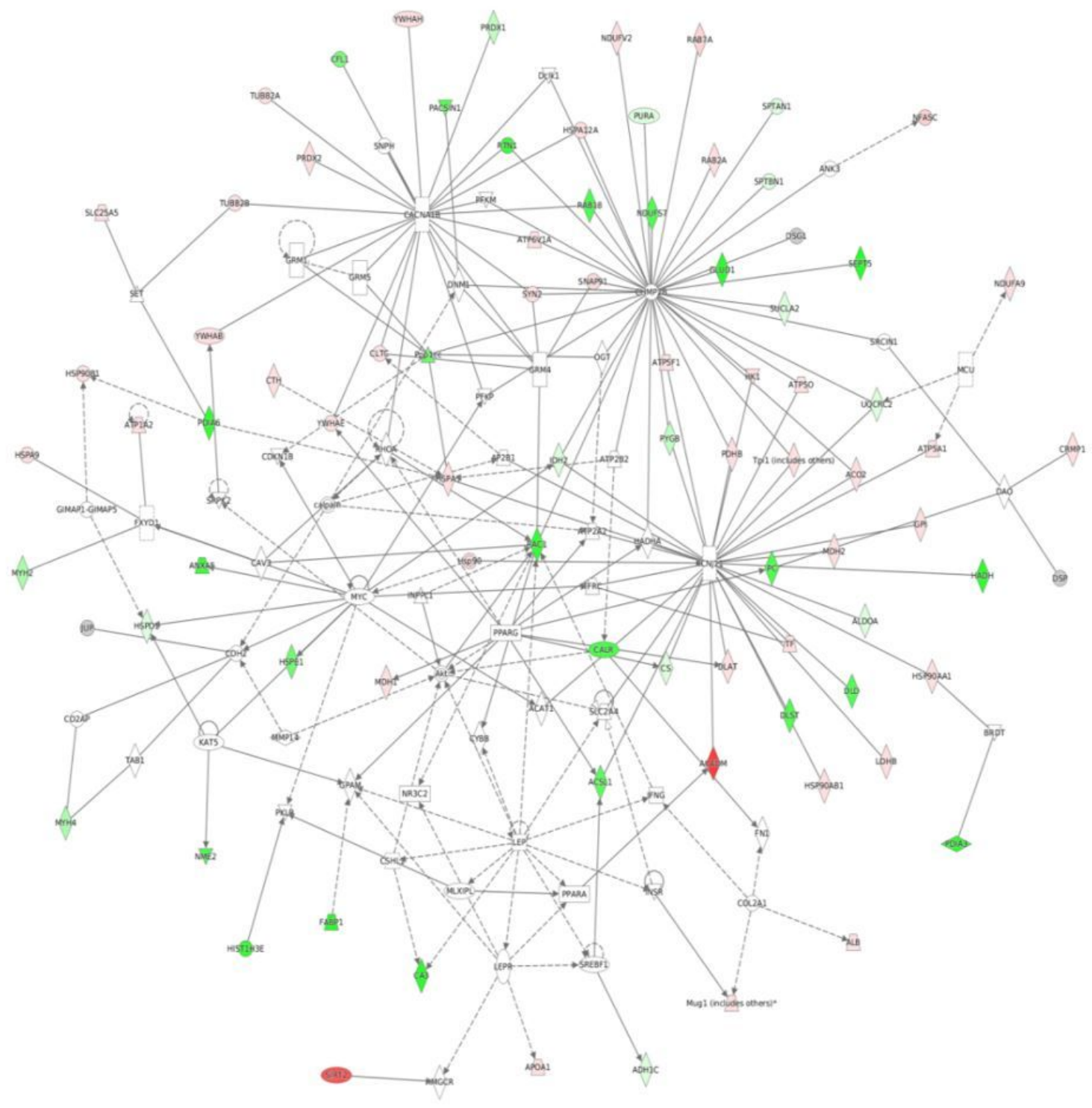

Figure 2

Integrated pathway analysis (IPA) of $A D$ versus $A E$ rat groups. 